\title{
Optimizing the thermal performance of building envelopes for energy saving in underground office buildings in various climates of China
}

\section{Article}

Accepted Version

Creative Commons: Attribution-Noncommercial-No Derivative Works 4.0

Shi, L., Zhang, H., Li, Z., Luo, Z. and Liu, J. (2018) Optimizing the thermal performance of building envelopes for energy saving in underground office buildings in various climates of China. Tunnelling and Underground Space Technology, 77. pp. 26-35. ISSN 0886-7798 doi:

https://doi.org/10.1016/j.tust.2018.03.019 Available at https://centaur.reading.ac.uk/76214/

It is advisable to refer to the publisher's version if you intend to cite from the work. See Guidance on citing.

To link to this article DOI: http://dx.doi.org/10.1016/j.tust.2018.03.019

Publisher: Elsevier

All outputs in CentAUR are protected by Intellectual Property Rights law, including copyright law. Copyright and IPR is retained by the creators or other copyright holders. Terms and conditions for use of this material are defined in the End User Agreement. 


\section{www.reading.ac.uk/centaur}

\section{CentAUR}

Central Archive at the University of Reading

Reading's research outputs online 

underground office buildings in various climates of China

3 Luyang $\mathrm{Shi}^{1}$, Huibo Zhang ${ }^{2}$, Zongxin $\mathrm{Li}^{3}$, Zhiwen Luo ${ }^{4}$, Jing Liu ${ }^{1,5^{*}}$

$4 \quad{ }^{1}$ School of Municipal and Environmental Engineering, Harbin Institute of Technology, 202 Haihe

5 Street, Nangang District, Harbin, China

$6 \quad{ }^{2}$ School of Naval Architecture, Ocean and Civil Engineering, Shanghai Jiao Tong University, 800

7 Dongchuan Road, Minhang District, Shanghai, China

$8{ }^{3}$ The Fourth Design and Research Institute, Headquarters of the General Staff Corps, Beijing, China

$9 \quad{ }^{4}$ School of the Built Environment, University of Reading, Reading, United Kingdom

${ }^{5}$ State Key Laboratory of Urban Water Resource and Environment, Harbin Institute of Technology, Harbin, China

(2.

$7 \quad{ }^{*}$ Corresponding author: Jing Liu

Address: School of Municipal and Environmental Engineering, Harbin Institute of Technology, No.73,

Huanghe Road, Nangang District, Harbin 150000, China.

Tel./fax: +86045186282123.

E-mail: liujinghit0@163.com 
Abstract This article investigates the influence of the thermal performance of building envelopes on annual energy consumption in a ground-buried office building by means of the dynamic building energy simulation, aiming at offering reasonable guidelines for the energy efficient design of envelopes for underground office buildings in China. In this study, the accuracy of dealing with the thermal process for underground buildings by using the Designer's Energy Simulation Tool (DeST) is validated by measured data. The analyzed results show that the annual energy consumptions for this type of buildings vary significantly, and it is based on the value of the overall heat transfer coefficient (U-value) of the envelopes. Thus, it is necessary to optimize the U-value for underground buildings located in various climatic zones in China. With respect to the roof, an improvement in its thermal performance is significantly beneficial to the underground office building in terms of annual energy demand. With respect to the external walls, the optimized U-values completely change with the distribution of the climate zones. The recommended optimal values for various climate zones of China are also specified as design references for public office building in underground in terms of the building energy efficiency.

Keywords: Underground office buildings; Thermal performance; Optimization; China; DeST simulation 


\section{Introduction}

In the view of the significant increases of the population in urban cities over recent decades, underground buildings have played an increasingly important role in the development and improvement of metropolises. A growing number of underground buildings, such as underground parking spaces, shopping malls, hospitals, railways, and office buildings, have been constructed as alternatives for urban area expansion in metropolises worldwide [1], and especially in China [2, 3]. For instance, the total area of underground space in Beijing has reached 72.68 million $\mathrm{m}^{2}$ with a noted annual increase of over 7.3 million $\mathrm{m}^{2}$ based on published figures in August 2014 [2]. The development of underground buildings effectively relieves land utilization in these mega cities, and definitely provides more living space for urbanites [4, 5]. Moreover, compared to buildings built above the ground, underground buildings may exhibit increased advantages in terms of building energy efficiency and indoor climate owing to their better capacities for heat storage, heat stability, and smaller temperature variations $[6,7]$. Therefore, underground buildings require lower heating and cooling loads, save more energy for residents, and improve urban sustainability [6, 7, and 8]. Many studies have demonstrated that underground buildings possess immense potential in reducing energy demands that can save more than $23 \%$ of energy in comparison with similar aboveground buildings [6, 9, 10, and 11]. It should be noted that the energy analysis of earth-sheltered domestic buildings situated in Poland showed that approximately $47 \%-80 \%$ reduction in the heating energy demand could be achieved by using various thickness of thermal insulation [6]. 
Recently, some researchers have attempted to study the energy performance of underground buildings using various research methods such as a two-dimensional transient finite element model (FEM) to investigate heat loss in a basement [12], a two-dimensional dynamic model of heat transfer through building envelopes using MATLAB [13], a combination of computer programs FlexPDE and EnergyPlus to simulate the heating and cooling energy demands in earth-sheltered buildings [6], a three-dimensional analysis of the thermal resistance of an external insulation system of a basement [13], a three-dimensional finite difference model (FDM) to verify the energy reduction potential of underground buildings [14], and an experimental analysis of indoor temperature variations related to ground layers in underground wine cellars [15]. All these experimental and simulated research studies indicate that the energy performance of underground buildings is determined by a wide variety of influential factors such as design typology, building function, HVAC systems, covering soil depth and type, thermal insulation, air infiltration [8]. In terms of design typology, contact surface area of building with the earth plays a key role in heat transfer. Overall, adopted methodologies have been more sophisticated as compared to conventional methodologies used for buildings above the ground. Additionally, these factors interact and change with different outdoor climates and indoor conditions $[8,16]$. Among these factors, the building envelope is a factor that can be easily designed and optimized in the early design stages for energy efficiency. In terms of building envelope features for aboveground buildings, an improvement in the thermal performance of the envelope, such as an increase in the thermal 
insulation level, can effectively reduce heat loss, and the annual energy demands for both heating and cooling $[17,18]$. The efficiency requirements for building envelopes, such as the assembly's maximum U-value (overall heat transfer coefficient), are determined for building energy efficiency based on the ASHRAE Standards 90.12016 [19] in America, and GB50189-2015 in China [20]. However, the heat transfer through an underground building is completely different from that of a building that is above the ground because the soil's thermal properties are treated as a thermal reservoir for modulating interior temperatures [21]. Therefore, these standards correspond to buildings built above the ground and might be not suitable for underground buildings in which the thermal performance of the envelopes is designed for energy efficiency.

In this context, several researchers have focused on the investigation of the influence of the thermal performance of the envelopes on energy consumption with respect to heating and cooling loads for underground buildings [11, 13, 22, and 23]. Krarti and Choi demonstrated that additional insulation is required at the corners, as opposed to the middle section of the surface to minimize the heat loss for underground buildings, and that insulation material should be close to the soil surface [13]. Yuan et al. evaluated the effect of building materials on the temperature and heat flux for envelopes in a basement, and indicated that the thermal conductivity of building materials is an important factor in the heat transfer of the envelopes [22]. Dronkelaar stated that the energy performance is more significantly dependent on the U-value of the constructions and the ventilation rates in certain colder climates [11]. 
111 Staniec and Nowak suggested that thinner thermal insulation, elicits a better cooling

112 effect gained from the soil, whereas a thicker insulation leads to a smaller heating

113 energy demand $[6,23]$. These studies indicates that the thermal performance of the

114 envelopes in an underground building is one of the most important design criteria to

115 allow the best thermal comfort effect [8]. However, the relationships between the

116 annual energy demand and the thermal performance of the envelopes in underground

117 buildings might not be very accurate and explicit, especially with respect to various

118 climatic zones. In general, outdoor climatic conditions have a slight influence on the

119 indoor environment and energy demand for underground buildings in a short time.

120 However, the long-term distribution of ground temperature is crucial in determining

121 the energy demand, which is dependent on the climate and soil's thermal properties.

122 Although the simulated analysis by Staniec and Nowak illustrated the influence of

123 thermal insulation on heating and cooling loads, the combined effect of thermal

124 performance of the envelope on the annual energy demand (including heating and

125 cooling energy) has not been considered in their study. Furthermore, their simulation

126 was only performed for Polish climate conditions, and thus, it may not be possible to

127 apply their conclusions to various climates around the world.

128 On the other hand, China has a vast territory spanning five different climatic

129 conditions [24]. Specifically, temperature waves of underground spaces differ in

130 terms of values, amplitude, period, and phase displacement for various climatic zones.

131 Therefore, the efficiency requirements of building envelopes in an underground

132 building may vary significantly with changes in the climate. Hence, a reasonable and 
formal guideline, or a standard listing the efficiency requirements, are necessary for underground building envelopes in various climates to provide a basis for the energy-saving design of the envelopes, which is currently lacking in China.

The aim of this study is to investigate the influence of the thermal performance of the envelopes on annual energy consumption for underground office buildings in various climatic zones of China, thereby allowing the determination of the optimized U-value for building envelopes (including the roof and the exterior wall), and introducing reasonable guidelines for the energy efficient design of underground building envelopes. First, a building energy simulation tool known as the Designer's Energy Simulation Tool (DeST) was presented in detail to deal with the thermal process for the underground building and the accuracy of DeST is also validated by measured data. Thus, DeST is used to calculating the hourly heating and cooling loads for ground-buried office buildings in this study to optimize the thermal performance of the insulation configurations of envelopes for various climatic zones in China, based on the annual energy consumption.

\section{Methodology}

This section is organized in four parts. Section 2.1 describes the details for simulating thermal process within underground buildings by means of DeST. Section 2.2 presents a prototype underground building model implemented in the DeST platform. Section 2.3 shows the classification of climate zones in China and lists the ten major Chinese cities selected for this simulation. The evaluation method of 
calculating annual energy demand based on hourly heating and cooling loads is summarized in Section 2.4.

\subsection{Simulation tool}

DeST is an effective building energy simulation tool that was developed by Tsinghua University in 1989. To-this-date, numerous case analyses and theoretical validations are performed, and as a result, DeST has become a widely-used platform for calculating building thermal processes and for dynamic simulations of the building's energy distribution. Specifically, DeST develops a graphical user interface that is based on AutoCAD for all simulation processes to avoid additional modelling work and information loss due to conversion [25].

In terms of energy performance, the most significant difference between an underground building and an aboveground building is that all the building partitions are in contact with soil, rather than atmosphere. Therefore, it is critical to determine surrounding ground temperature and calculate the heat transfer process of ground-coupled envelopes that are in contact with the earth for simulating an underground building. Generally, heat transfer within ground-coupled envelope is computed using numerical methods, such as FEM and FDM $[12,14]$. However, these models are excessively time-consuming for hourly simulations over the period of a year [25].

In DeST simulation, the heat transfer process of ground-coupled envelopes (the envelopes that are contact with the earth) is decomposed into three processes which 

surface temperature and temperature difference of ground-coupled envelope surfaces [26]. The schematic diagram of heat transfer within ground-coupled envelopes is

178 presented in Fig.1. Outdoor ground surface temperature (OGST) is mainly determined by above air temperature, absorbed solar radiation, long wave radiation with sky. Ground-coupled envelope surface temperature is mainly determined by room air temperature, long wave radiation with occupant, light, equipment and other inner surface in the room. Temperature of deep soil surface is set as constant and approximately equals to mean ground surface temperature (MGST).

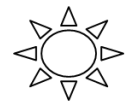

Outdoor air

Fig.1 Schematic program of underground building's heat transfer and boundary condition (not in scale)

In the first process, outdoor ground surface temperature is set as zero and the temperature of other ground-coupled envelopes is set the same as the selected one.

The heat transfer process controlled by ground-coupled envelope surface temperature is computed by one-dimensional Equivalent Slab. In the second process, temperature of all ground-coupled envelope surfaces is set as zero and outdoor ground surface temperature is simplified as a constant and 1 year period harmonic variable. In the 
third process, outdoor ground surface temperature is set as zero and the temperatures of ground-coupled envelopes are different. The heat between ground-coupled envelopes is exchanged through the soil and is computed by a one-dimensional Extra Partition Wall. Therefore, replace the ground-coupled envelope in a room using Equivalent Slab and treat the heat flux computed in the second and third process as heat source of Equivalent Slab inner surface, and thus the heat transfer of ground-coupled envelope is calculated and implemented into building thermal simulation. This approach can save a large amount of time for the full-year calculation compared with other numerical methods [26].

\subsection{Underground office building details}

All simulation stages are performed in DeST for a simplified prototype building model based on a typical large-scale office building that is fully underground. The building is located at a depth of $1.0 \mathrm{~m}$ below the ground in Beijing and has only one underground floor with a story height of $3.3 \mathrm{~m}$. The building is consisted of five sections as detailed in a previous study [27]. Fig.2 shows the layout of the eastern section of the building as the chosen prototype building model in the calculation, which has a building area of $215.5 \mathrm{~m}^{2}$. Table 1 lists the components and thermal performance of the building envelope. The building is surrounded by rammed clay that is considered as a special component for the exterior walls. The thermal conductivity coefficient of rammed clay is $1.16 \mathrm{~W} /(\mathrm{m} \cdot \mathrm{K})$. 


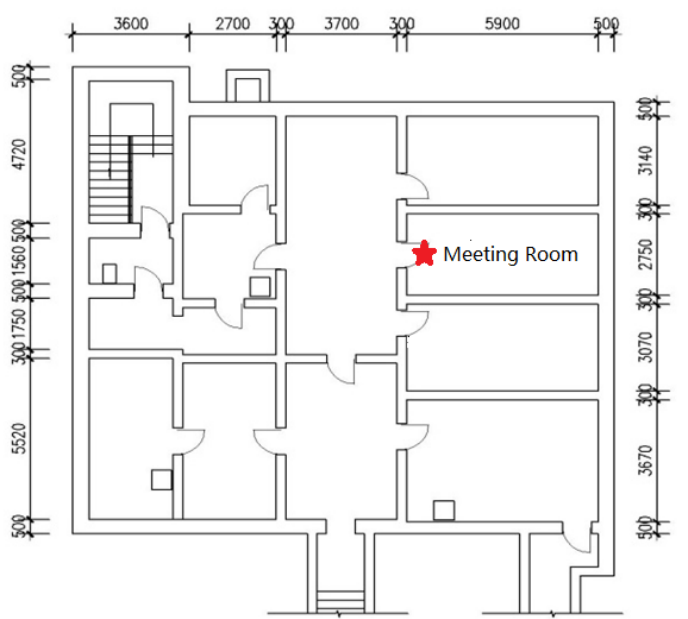

Fig.2 The layout of the simplified underground building (unit: $\mathrm{mm}$ )

Table 1 Components and the thermal performance of the building envelope

\begin{tabular}{lll}
\hline $\begin{array}{l}\text { Building } \\
\text { envelope }\end{array}$ & Building envelope components & $\begin{array}{l}\mathrm{U} \text {-value } \\
\left(\mathrm{W} / \mathrm{m}^{2} \cdot \mathrm{K}\right)\end{array}$ \\
\hline Roof & $20 \mathrm{~mm}$ Lime mortar $+300 \mathrm{~mm}$ reinforced concrete & 0.81 \\
External walls & $30 \mathrm{~mm}$ Lime mortar $+200 \mathrm{~mm}$ reinforced concrete & 1.00 \\
\hline
\end{tabular}

In this simulation, the layout and building structure are constructed using model parameters that are as close as possible to the real-life situation [28]. It is assumed that there is no infiltration or solar gains for the underground building because the building is completely buried beneath the surface.

Three scenarios are considered in the simulation. The details of building characteristics for the three scenarios are presented in Table 2. Scenario A is

221 performed to simulate annual indoor temperature variations in the meeting room as depicted in Fig.2. Scenarios B and C are both executed to calculate the hourly load of the underground building. First, Scenario B is performed to investigate the influence

224 of the U-value of the roof on the annual energy demand, and to determine its optimal $225 \mathrm{U}$-value. This is followed by the execution of Scenario $\mathrm{C}$ to optimize the thermal 
performance of the exterior walls. It should be noted that the U-value of the roof for

227 Scenario C is adopted based on the optimized results in Scenario B. In this study, two 228 covering soil depths $(1.0 \mathrm{~m}$ and $3.0 \mathrm{~m})$ (calculated between the rooftop of the 229 building and the ground surface) are chosen because the depth also greatly affects the 230 indoor heat environment of the subsurface structure [8]. In this simulation, the 231 research objective is the public office building, thus the parameters of the thermal 232 disturbances (Table 3) from the occupants, illumination, and equipment in the 233 building are assumed to be the same as those of public buildings above the ground according to Chinese national standard for public buildings [20], which is typical and representative for office buildings. The schedules for the interior heat sources are described in Table 4. Mechanical ventilation does not consider the impact of fresh air on the heat transfer between the building and surrounding envelopes. Therefore, the fresh air load is not included in the simulation for the calculation of the annual hourly load.

Table 2 Building characteristics for the three executed scenarios

\begin{tabular}{lllll}
\hline Scenario & $\begin{array}{l}\text { Depth } \\
(\mathrm{m})\end{array}$ & $\begin{array}{l}\mathrm{U} \text {-value of the roof } \\
\left(\mathrm{W} / \mathrm{m}^{2} \cdot \mathrm{K}\right)\end{array}$ & $\begin{array}{l}\text { U-value of the exterior } \\
\text { wall and floor }\left(\mathrm{W} / \mathrm{m}^{2} \cdot \mathrm{K}\right)\end{array}$ & $\begin{array}{l}\text { Internal heat } \\
\text { gains }\end{array}$ \\
\hline A & 3.0 & 0.81 & 1.00 & None \\
B & $1.0 / 3.0$ & Variable value & 1.00 & See Table 3 \\
C & $1.0 / 3.0$ & Optimal value & Variable value & See Table 3 \\
\hline
\end{tabular}

241 Notes: Variable values: 0.22/0.49/0.81/1.00/1.50/2.00/2.45/2.97, optimal value: the optimized results of

\begin{tabular}{llll}
\hline Building function & $\mathrm{MNP}\left(\right.$ people $\left./ \mathrm{m}^{2}\right)$ & $\mathrm{MI}\left(\mathrm{W} / \mathrm{m}^{2}\right)$ & $\mathrm{MHGFE}\left(\mathrm{W} / \mathrm{m}^{2}\right)$ \\
\hline
\end{tabular}




\begin{tabular}{llll} 
Public office & 0.1 & 9.0 & 15 \\
\hline
\end{tabular}

Notes: MNP: maximum number of individuals, MI: maximum illumination, MHGFE: maximum heat

Table 4 Schedules for various internal heat sources

\begin{tabular}{ll}
\hline Interior disturbance & Schedule \\
\hline Occupants & ON from 08:00 to 17:00 on workday, OFF at all other times \\
Illumination & ON from 08:00 to 17:00 on workday, OFF at all other times \\
Equipment & ON from 08:00 to 17:00 on workday, OFF at all other times \\
\hline
\end{tabular}
provision of a comfortable indoor environment in an underground building. The high heat storage capacity of the surrounding soil results in an indoor underground temperature that is lower than $20^{\circ} \mathrm{C}$ sometimes even during the summer [15, 27], and parameters for an underground space to those used for indoor air conditioning for

253 buildings above the ground, such as $26^{\circ} \mathrm{C}$ in the summer, and $20^{\circ} \mathrm{C}$ in winter. In the 254 simulation, the indoor temperatures of an underground building in the summer and 255 winter were set to a wide range of temperatures that approximately spanned $20-28{ }^{\circ} \mathrm{C}$, 256 and $18-22^{\circ} \mathrm{C}$, respectively.

\subsection{Climatic zones in China}

258 Based on the different climatic characteristics, China is divided into five major 259 climate zones as follows: a severe cold zone (SCZ), a cold zone (CZ), a hot summer 260 and cold winter zone (HSCWZ), a hot summer and warm winter zone (HSWWZ), and 261 a temperate zone (TZ) (Fig.3). This climatic classification framework is principally 


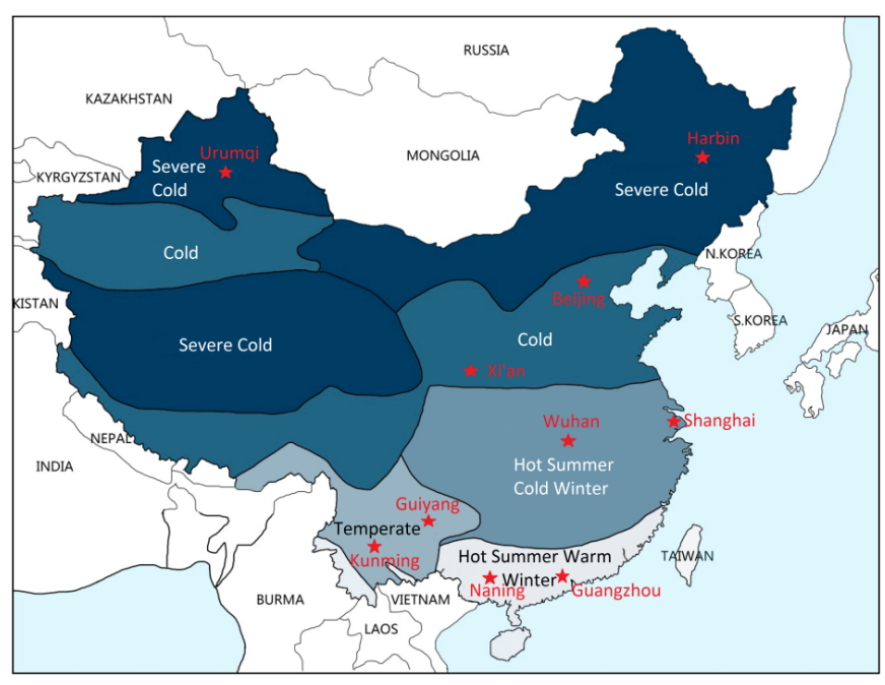

Fig.3 Classification of climate zones in China and geographic locations of the 10 major cities selected

For Scenario B and C, 10 typical cities covering the climate zones are selected for represent the corresponding climatic zones. The meteorological data for these cities during a typical meteorological year is determined based on a multiyear weather database file [16]. In DeST, hourly data of weather variations is calculated in a similar manner to the calculation of the weather input parameters for Scenario B and C.

\subsection{Annual energy demand calculation}

The hourly heating and cooling loads for the underground building are obtained based on the calculations of Scenario B and C. The grades of energy used in the

275 heating and cooling systems as well as their energy efficiencies are different. It is 276 necessary to convert the various energy forms to electricity power by using the 
method detailed in the GB50189-2015 Standard [20], and thus annual energy consumption for underground building is obtained.

For all the climatic zones, space cooling is provided using water-cooled centrifugal chillers [20], and the electricity consumption for cooling can be calculated in accordance to Eq.(1):

$$
E_{C}=\frac{Q_{C}}{A \times S C O P_{T}}
$$

where, $\mathrm{Q}_{C}$ denotes the accumulative cooling load on the calculated DeST results in $\mathrm{kWh}$, A denotes the total cooling areas in $\mathrm{m}^{2}$, and $\mathrm{SCOP}_{T}$ is the synthetic coefficient of performance for the cooling system and equals to 2.5 [20].

The heating system is determined based on the climate zones. The system operation with a coal-fired boiler is applied in the $\mathrm{SCZ}$ and $\mathrm{CZ}$, while the system that operated with a natural-gas-fired boiler is applied in all the other climate zones [23]. The electricity consumption for the heating system can be evaluated using Eqs.(2) and (3), respectively.

$$
E_{H}=\frac{Q_{H}}{A \eta_{1} q_{1} q_{2}}
$$

where, $\mathrm{Q}_{H}$ denotes the annual accumulative heating load based on the calculated results of DeST in $\mathrm{kWh}, \mathrm{A}$ denotes the total heating areas in $\mathrm{m}^{2}, \eta_{1}$ denotes the synthetic efficiency of the heating system with a coal-fired boiler and equals to $60 \%$ [20], $\mathrm{q}_{1}$ denotes the calorific value of standard coal and equals to $8.14 \mathrm{kWh} / \mathrm{kgce}$, and $\mathrm{q}_{2}$ denotes the coal consumption rate in the power generation and equals to $0.360 \mathrm{kgce} / \mathrm{kWh}$.

$$
E_{H}=\frac{Q_{H}}{A \eta_{2} q_{3} q_{2}} \varphi
$$


Where, $\varphi$ denotes the converted coefficient between standard coal and gas, and

300 equals to $1.21 \mathrm{kgce} / \mathrm{m}^{3}, \eta_{2}$ denotes the synthetic efficiency of the heating system

301 with a natural gas-fired boiler and equals to $75 \%$ [20], and $\mathrm{q}_{3}$ denotes the calorific

302 value of gas and equals to $9.87 \mathrm{kWh} / \mathrm{kgce}$.

303 Finally, the annual energy consumption is the sum of $\mathrm{E}_{H}$ and $\mathrm{E}_{C}$, and is 304 considered as the evaluation index of the total energy consumption for a full year in 305 this study.

\section{Results and discussions}

\subsection{Analysis of room temperature simulation}

Basal room temperature refers to the indoor temperature that arises from the thermal interaction between the outdoor climatic conditions and the building in its natural state [16]. In this case, there were no heating/cooling sources or working HVAC systems. In this study, the meeting room, denoted as a red star in Fig.2, was used as an example to analyse the indoor temperature variations throughout the entire year. Fig.4 (a) shows the measured indoor temperature data a period of 9-10 months, while the outdoor temperature variations of Beijing during the year at which tests were conducted are shown in Fig.4 (b). Additionally, the annual hourly basal room temperature of the meeting room was calculated using DeST (Scenario A), as presented in Fig.4 (a). It should be noted that the meteorological data for Scenario A were based on a weather database file that matched the year at which the tests were conducted. 

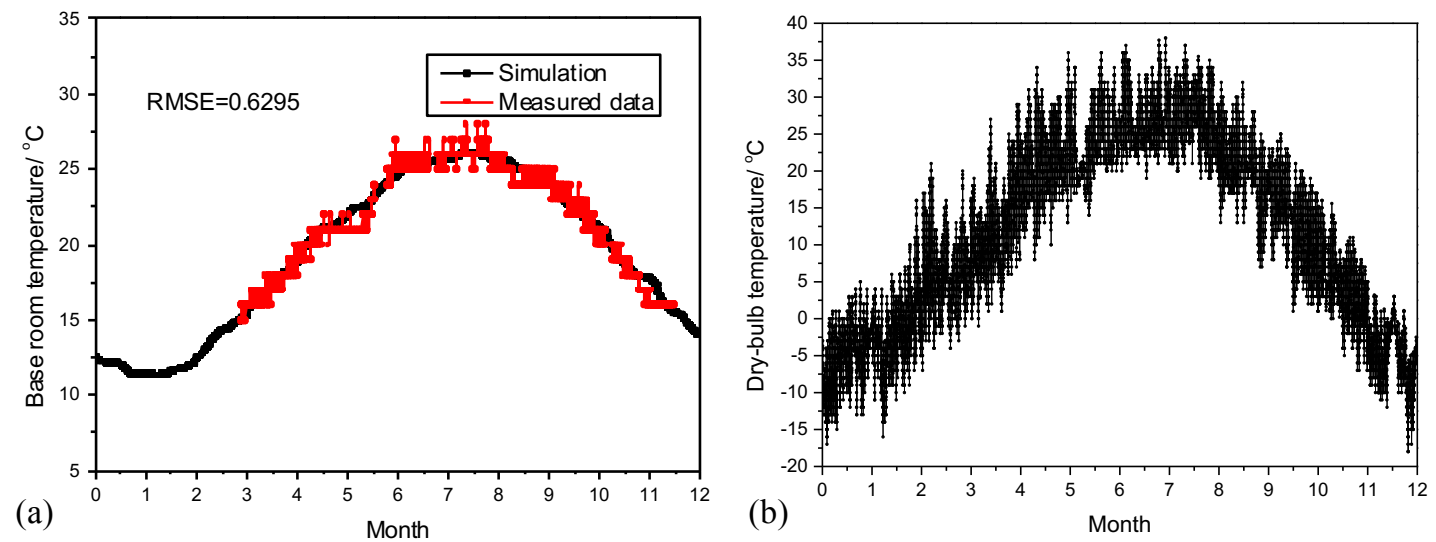

Fig.4 Basal temperature variations in the meeting room for simulation and measurements (a) and annual hourly dry-bulb temperature in Beijing during the testing year at which tests were conducted (b)

A sinusoidal behaviour of seasonal variability in the indoor temperature of the meeting room is distinctly observed in Fig.4. A comparison of the variations of indoor and outdoor temperatures indicates that their behaviours are almost identical in terms of the exhibited tendencies to monthly changes, but the temperature waves differ in terms of values, amplitude, and phase displacement [15]. First, the indoor temperature is very stable throughout the year eliciting a mean temperature of approximately $20{ }^{\circ} \mathrm{C}$ when compared to the outdoor temperature owing to the thermal inertia of the surrounding soil. The highest temperature of the underground space is approximately $10{ }^{\circ} \mathrm{C}$ lower than that of the outdoor air, while the lowest temperature of underground space is more than $20{ }^{\circ} \mathrm{C}$ larger than that of outdoor air. Additionally, the highest indoor temperature in underground buildings occurred in early August, while the highest outdoor temperature occurred in early July. Similarly, the lowest indoor temperature of the underground space is observed in mid-February, while the lowest outdoor temperature is observed in mid-January. This implies that the phase displacement between the indoor temperature in the underground space (at a depth of 
$1.0 \mathrm{~m}$ below the ground) and the outdoor temperature approximately corresponds to one month.

In order to compare the calculated and measured indoor temperature of the meeting room, we calculated the coefficient of variation of the root-mean square error

(RMSE) using the following equation:

$$
\mathrm{RMSE}=\sqrt{\sum_{i=1}^{N}\left(T_{\text {meas }}-T_{\text {model }}\right)^{2} / N}
$$

modelled indoor temperature at that same time, and $N$ is the number of measurements.

The value of RMSE is used to quantify the agreements between measured and computational results and this value in Fig.4 (a) is 0.63 , showing there is a good agreement between that experimental and computational results. Thus, the accuracy of the thermal process within underground buildings by means of DeST-based dynamic simulation is thus validated.

\subsection{Analysis of hourly load for heating and cooling.}

an example. In this case, the details of the simulation are as follows: the building is located at a depth of $1.0 \mathrm{~m}$ below the ground (Beijing), and the heat transfer coefficient of the roof is $0.8 \mathrm{~W} /\left(\mathrm{m}^{2} \cdot \mathrm{K}\right)$. Fig.5 shows the simulation results for the distribution of annual hourly heating and cooling loads in an underground building. 

until the beginning of September, and this indicated that the cooling system worked during this period to regulate the indoor temperature to preset levels. The onset of the cooling operation occurred a month later than that used for buildings built above the ground. This may be owing to the phase displacement of the ground temperature compared to the outdoor temperature. A similar tendency in the heating load is also observed in Fig.5. For an underground building, the heating system mainly worked from January to February instead of the coldest months with respect to the outdoor atmosphere in Beijing (December and January).

\subsection{Impact of thermal characteristics of the roof on building energy demand}

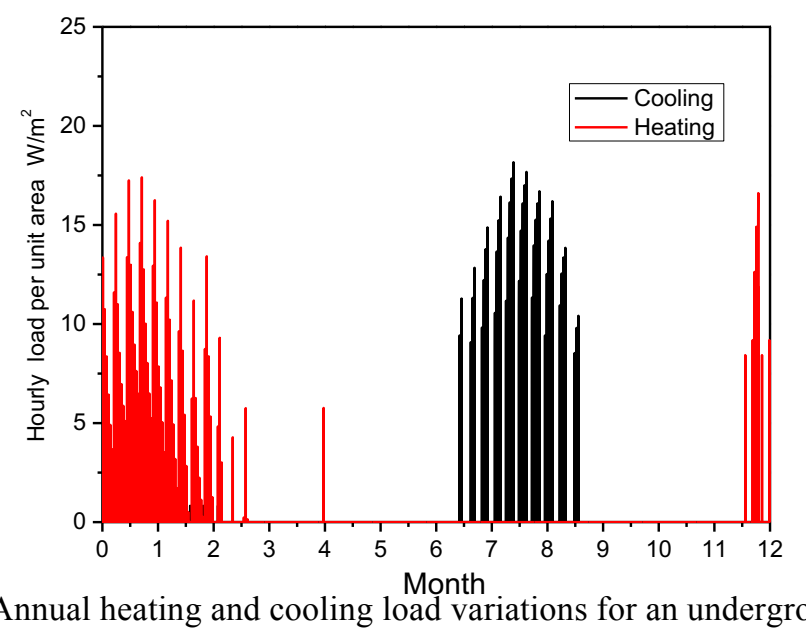


U-values for the roofs for various climatic zones of China are very similar. Overall,

383 the decrease in the U-values of the roof effectively reduced the building's energy

384 demand by enhancing the thickness of the thermal insulation. This can be explained

385 by the fact that the existing insulation diminished the impacts of the outdoor climate

386 on the indoor environment of an underground space. For example, in Harbin (with a

387 building depth of $1.0 \mathrm{~m}$ ), the amount of annual energy consumption decreased from

$3886.20 \mathrm{~kW} \cdot \mathrm{h} / \mathrm{m}^{2}$ to $3.55 \mathrm{~kW} \cdot \mathrm{h} / \mathrm{m}^{2}$, and this corresponded to a change of approximately

$38942.7 \%$ when the U-value decreased from $2.0 \mathrm{~W} /\left(\mathrm{m}^{2} \cdot \mathrm{K}\right)$ to $0.5 \mathrm{~W} /\left(\mathrm{m}^{2} \cdot \mathrm{K}\right)$. The

390 effectiveness of the U-value is more significant at lower values, while U-values

391 higher than $2.5 \mathrm{~W} /\left(\mathrm{m}^{2} \cdot \mathrm{K}\right)$ minimized their impacts on the building's energy

392 consumption.

393 Therefore, the analyzed results reveal that the energy efficiency requirements for 394 the roofs of underground buildings are consistent with the standards for buildings 395 above the ground. Thus, an improvement in the thermal performance of a roof, based 396 on the increase of the insulation materials, is beneficial to the building's energy 397 consumption. As shown in Fig.6 (a) and (b), it is also clear that additional insulation 398 materials are required for cold climatic zones-and especially for SCZ to minimize heat 399 loss through the roof, and especially for shallow-buried underground buildings. 

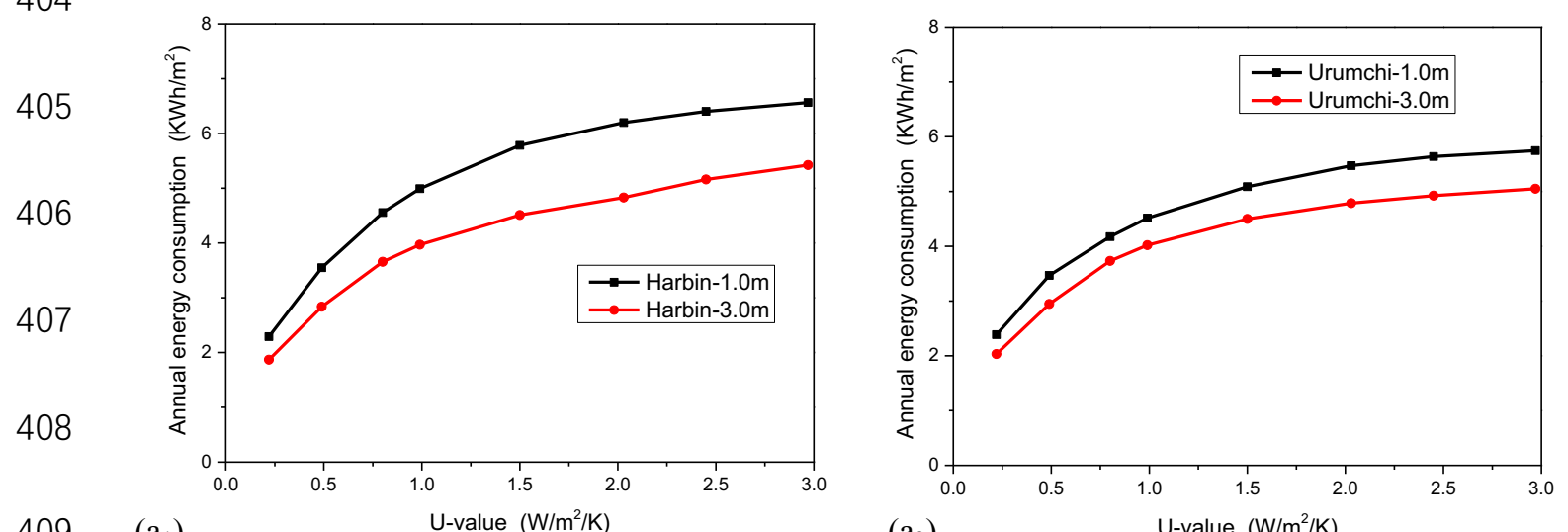

$409 \quad\left(a_{1}\right)$

$\left(a_{2}\right) \quad$ U-value $\left(\mathrm{W} / \mathrm{m}^{2} / \mathrm{K}\right)$
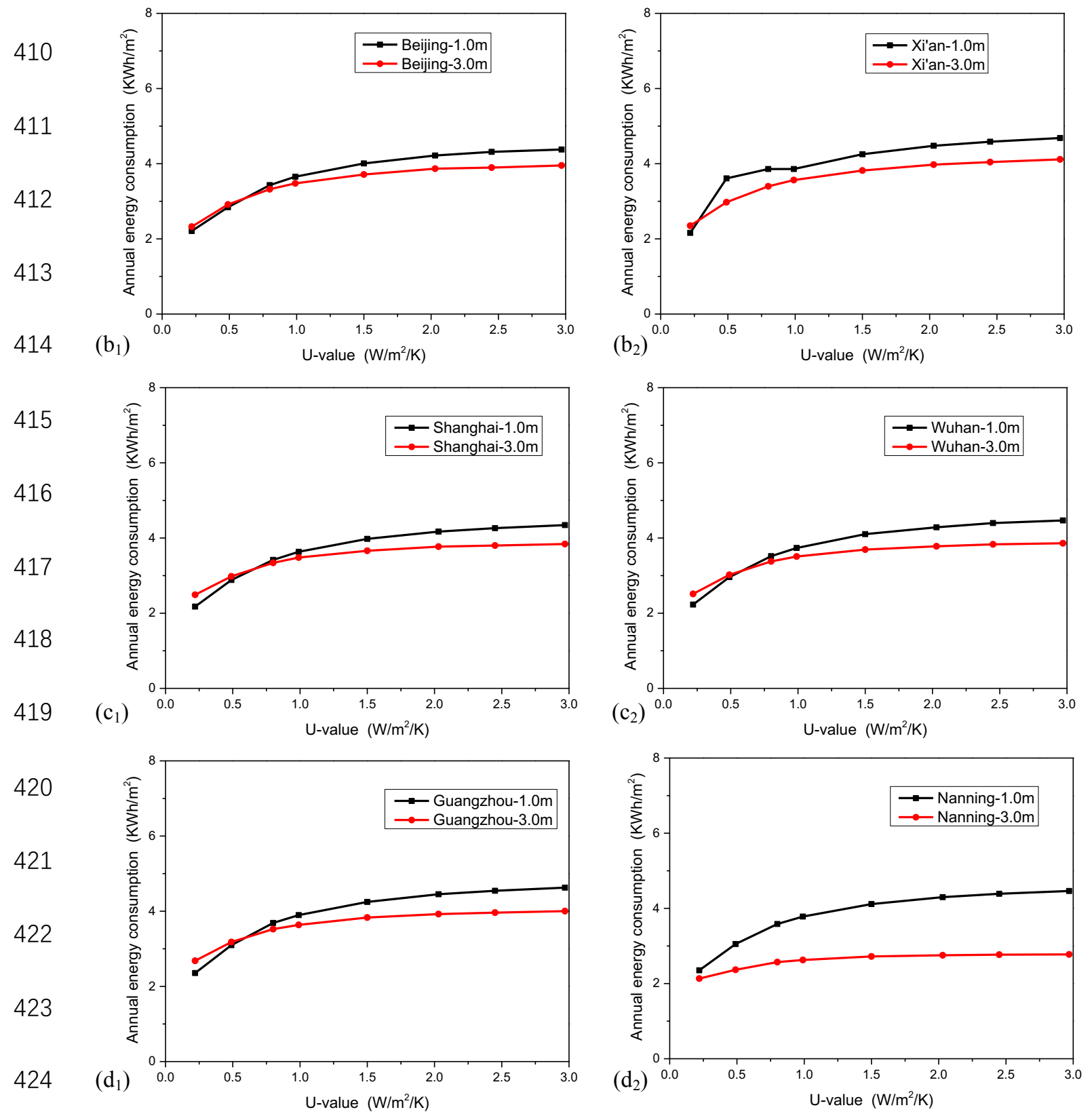


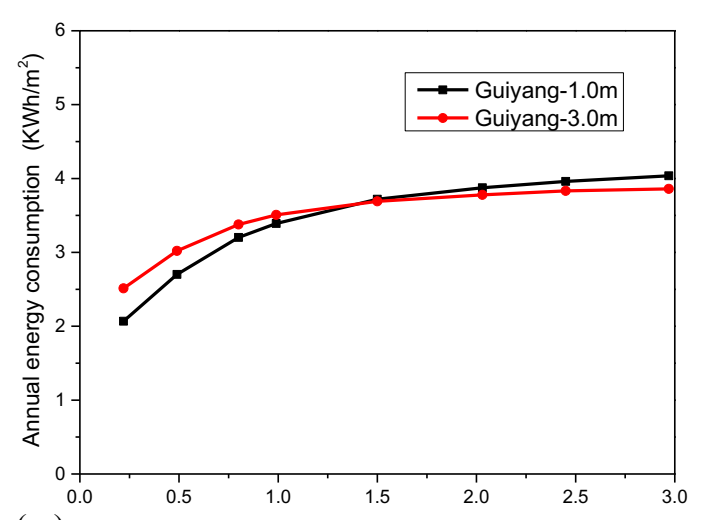

$\left(e_{1}\right)$

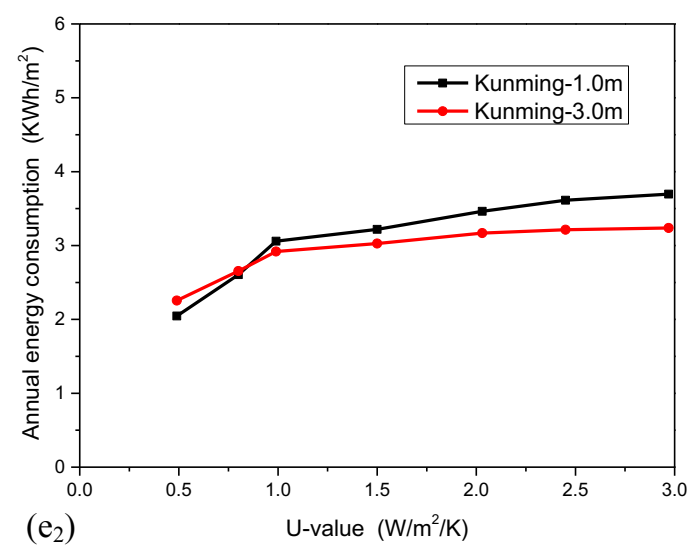

$\left(\mathrm{e}_{2}\right)$

Fig.6 Relationships between annual energy demand and U-values of the roof for SCZ (a), CZ (b),

China. Overall, these relationships vary with changes in the climate.
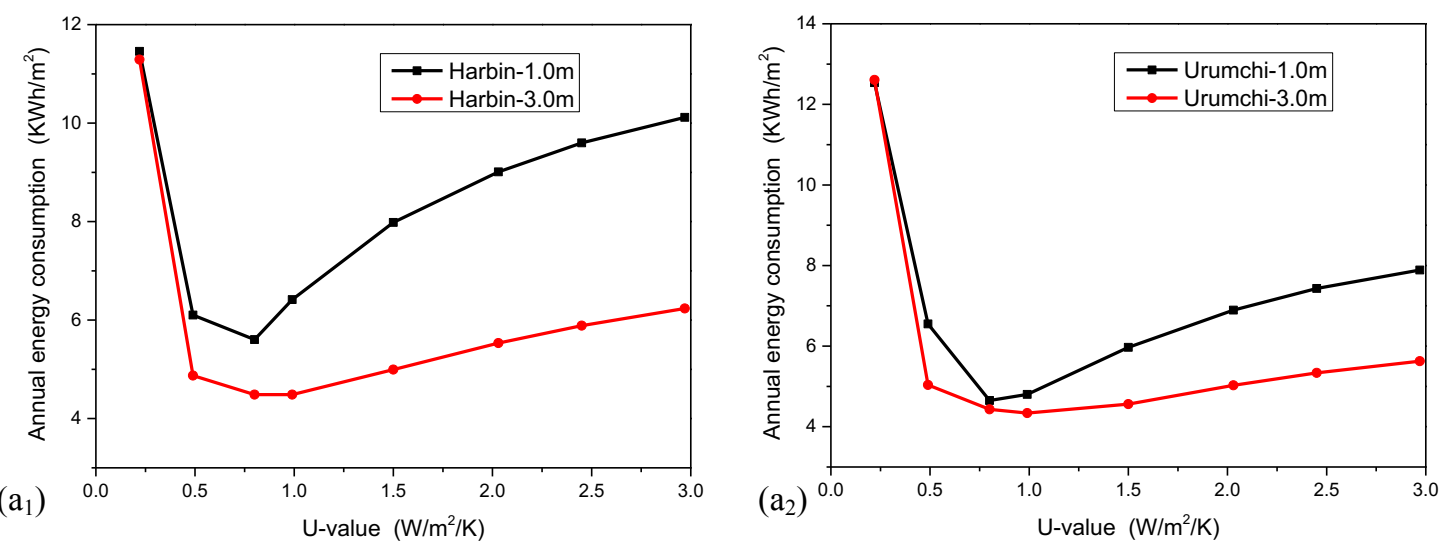

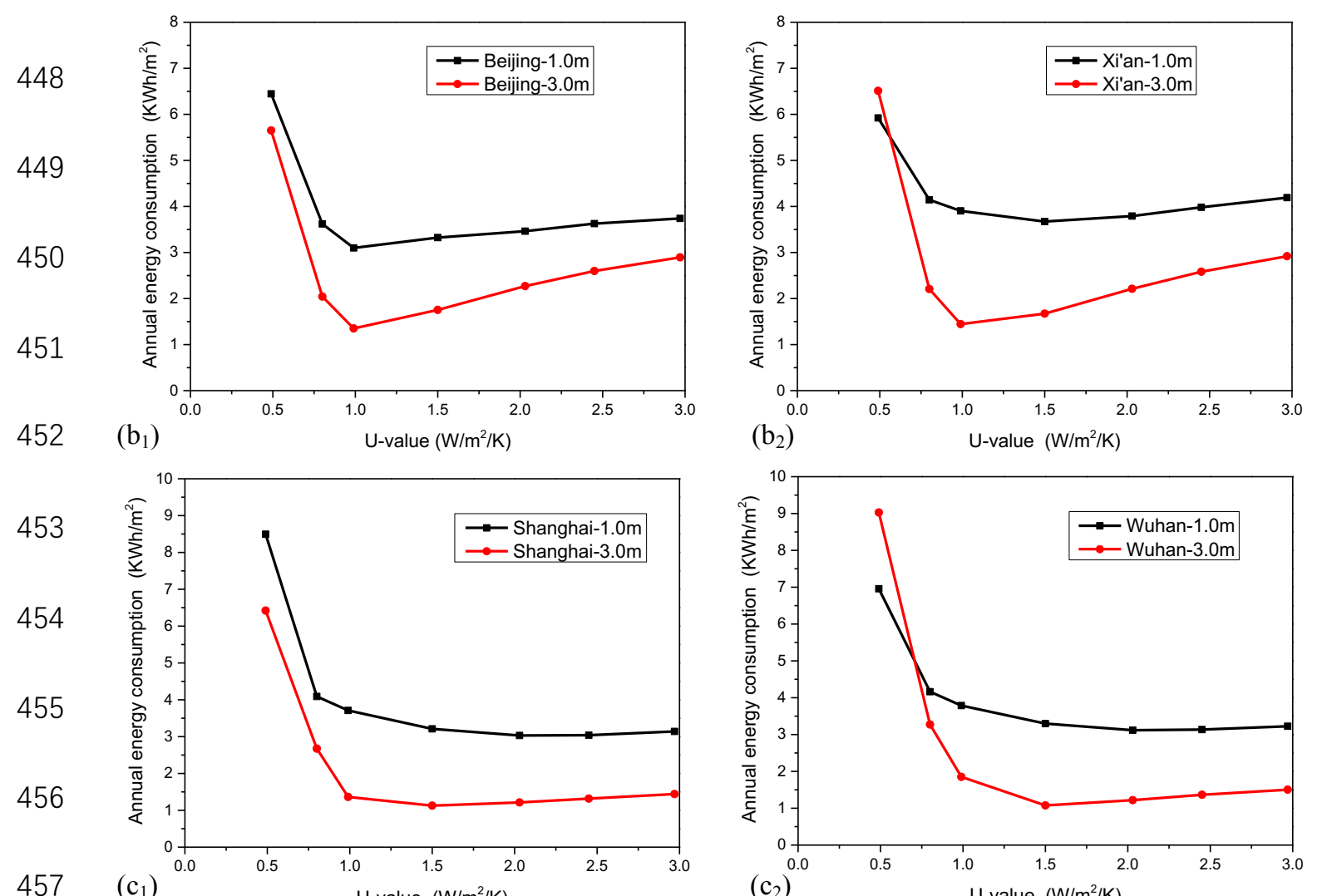

$\left(\mathrm{b}_{2}\right) \quad$ U-value $\left(\mathrm{W} / \mathrm{m}^{2} / \mathrm{K}\right)$
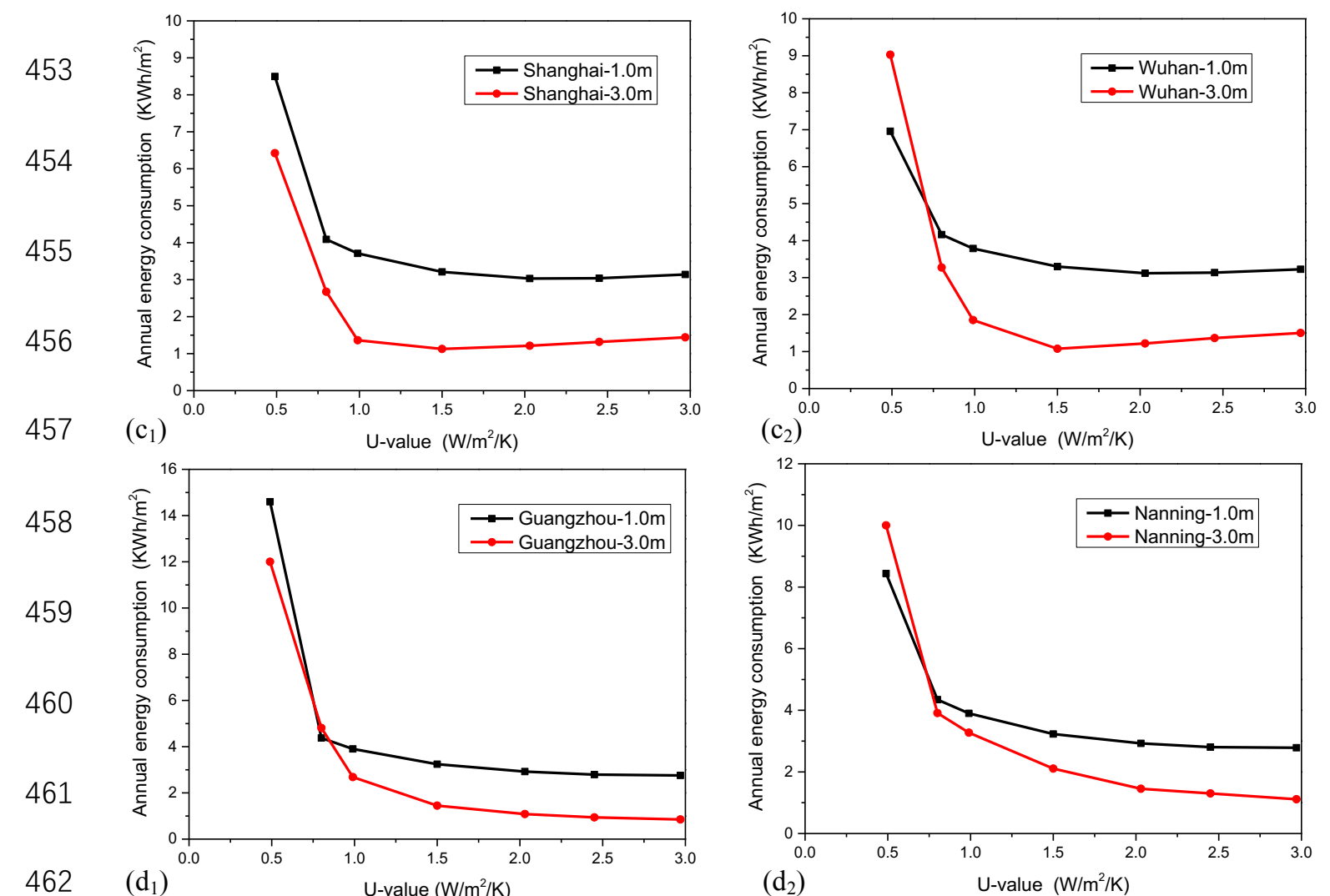

$\left(\mathrm{d}_{2}\right) \quad$ U-value $\left(\mathrm{W} / \mathrm{m}^{2} / \mathrm{K}\right)$
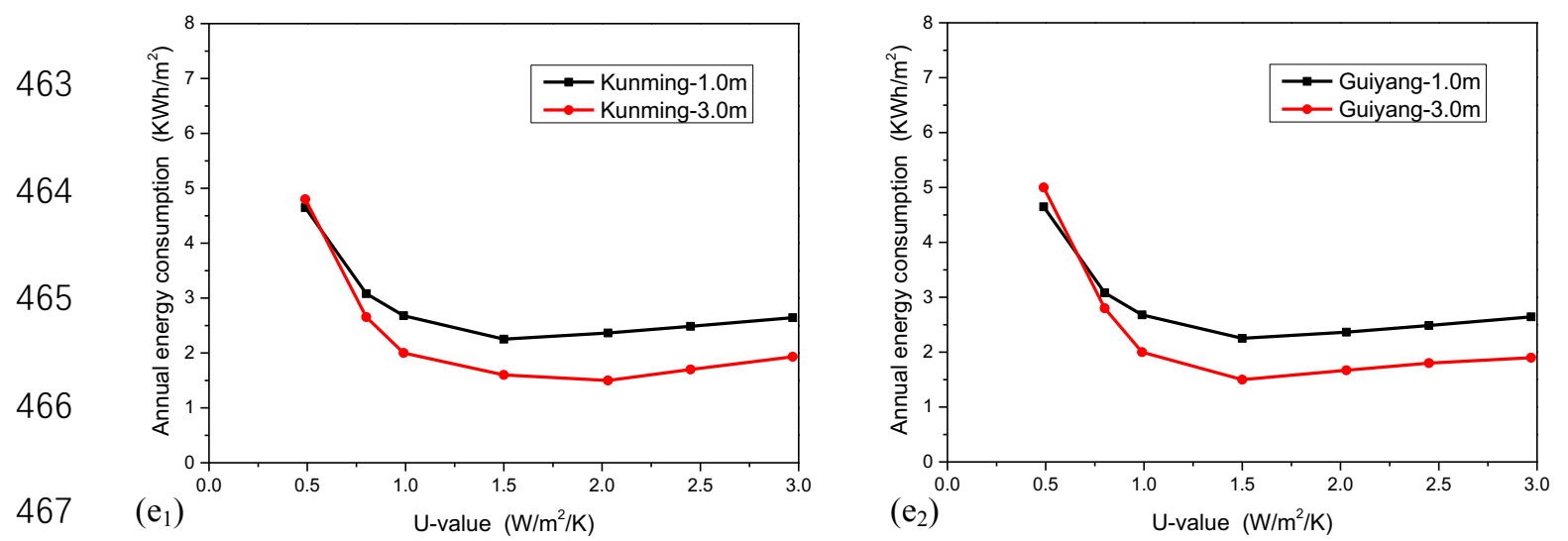

468 Fig.7 Relationships between annual energy demand and U-values of the exterior wall for SCZ (a), CZ 
470 A minimum is clearly observed in Fig.7 (a) and (b), thereby implying that there is 471 an optimal U-value for the exterior wall for SCZ and CZ. With respect to SCZ, it is 472 noted that increasing the $\mathrm{U}$-value from $0.22 \mathrm{~W} /\left(\mathrm{m}^{2} \cdot \mathrm{K}\right)$ to $0.8 \mathrm{~W} /\left(\mathrm{m}^{2} \cdot \mathrm{K}\right)$ effectively 473 reduces the annual energy consumption. However, this is followed by a continuous 474 increase in the annual energy demand as a function of the U-value. Thus, the optimum $475 \mathrm{U}$-value for the exterior wall for $\mathrm{SCZ}$ is approximately equal to $0.8 \mathrm{~W} /\left(\mathrm{m}^{2} \cdot \mathrm{K}\right)$. 476 Similarly, the optimum value of the exterior wall in an underground building for $\mathrm{CZ}$ is $477 \quad 1.0 \mathrm{~W} /\left(\mathrm{m}^{2} \cdot \mathrm{K}\right)$.

478 The reason pertaining to the achieved optimal level of the U-value of the exterior 479 wall is attributed to the differential impacts of energy consumption owing to heating 480 and cooling. Fig. 8 shows the variations in heating and cooling energies as a function 481 of the U-values of the exterior wall in Harbin. Specifically, the thermal resistance of 482 the exterior wall effectively prevents heat from being transferred into the surrounding 483 soil in winter. Nevertheless, if the U-value is excessively low, the heat generated in 484 the room cannot be effectively transferred into the soil, and this leads to an increased 485 cooling load. In the summer, a decrease in the U-value of the exterior wall can 486 effectively transfer more heat into the surrounding soil, and this is helpful in yielding 487 significant decreases in the indoor temperature and in the cooling load. Thus, a 488 decrease in the U-value of the exterior wall is beneficial in the reduction of the 489 heating energy in winter, while an increase in the U-value is helpful in reducing the cooling energy in the summer. It is necessary to evaluate a trade-off by considering 
the optimal annual energy consumption (including the heating and cooling energies) when the thermal performance of the exterior wall in an underground building is designed for energy conservation.

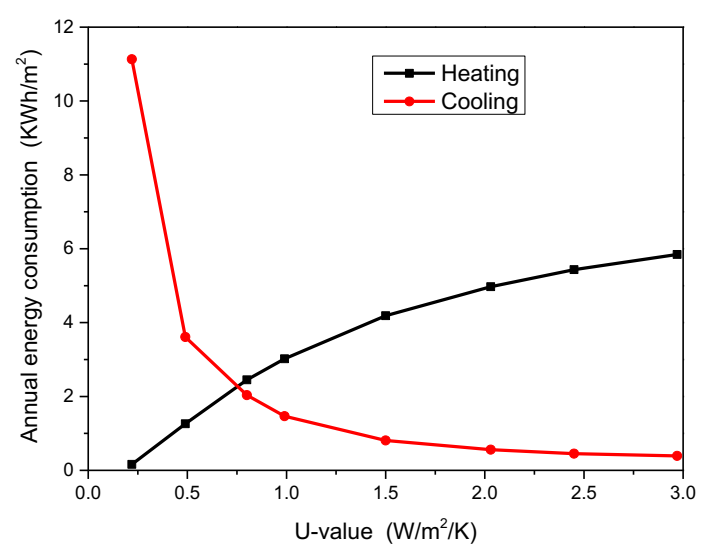

Fig.8 Variations in the annual energy consumption for heating and cooling as a function of U-values of the exterior wall in Harbin

With respect to the HSCWZ, the optimized value was approximately $1.5 \mathrm{~W} /\left(\mathrm{m}^{2} \cdot \mathrm{K}\right)$, but when the U-value increased to $2.0 \mathrm{~W} /\left(\mathrm{m}^{2} \cdot \mathrm{K}\right)$, its impact on building energy consumption was minimized. Similarly, the optimized U-value for TZ was approximately in the range of $1.5-2.0 \mathrm{~W} /\left(\mathrm{m}^{2} \cdot \mathrm{K}\right)$, as shown in Fig.7 (e). It should be noted that higher U-values elicit lower annual energy demand for buildings in HSCWZ, even though the effectiveness of the U-value is not significant at higher values. This means that thermal insulation materials are not necessary for the exterior walls in underground buildings for HSCWZ, and that the U-value of the exterior walls should in general be larger than $2.0 \mathrm{~W} /\left(\mathrm{m}^{2} \cdot \mathrm{K}\right)$. These findings are completely different from those for buildings above the ground. The main reason for this difference is the soil temperature. Fig.9 presents the measured data of the soil temperature at a depth of $3.2 \mathrm{~m}$ in a typical underground building in five selected 


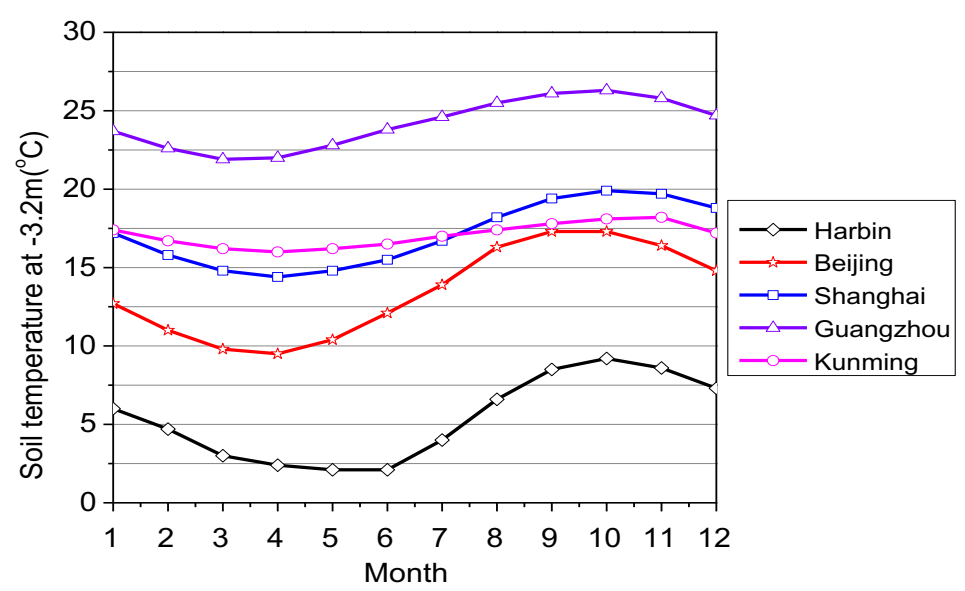

Fig. 9 Measured data of the soil temperature at a depth of $3.2 \mathrm{~m}$ below the ground

Based on Fig.9, it is observed that the average soil temperature corresponding to a depth of $3.2 \mathrm{~m}$ below the ground in Guangzhou (HSCWZ) reached $24{ }^{\circ} \mathrm{C}$, and that the yearly dry-bulb temperature exceeded $20^{\circ} \mathrm{C}$. Thus, cooling of the interior space constitutes the main consequence in response to the climatic changes of HSWWZ. Increasing the U-value of the exterior wall is helpful in transferring the heat generated in the space into the surrounding soil.

527 Conversely, the fluctuation in the soil temperature in Harbin (SCZ) and Beijing 528 (CZ) exceeded the corresponding fluctuations for the other three cities. For example, in Harbin, the average soil temperature (at a depth of $3.2 \mathrm{~m}$ below the ground) is the lowest among all the studied cities, and corresponded to approximately $5{ }^{\circ} \mathrm{C}$. Thus, it

531 is curial to reduce heat losses through the external walls. This is the reason why the 532 basic requirements of good thermal insulation of the envelope need to be met for SCZ and CZ. 
The focus of the present study is the thermal performance of the envelope for soil-buried office buildings, which may show distinct characteristics when compared to conventional buildings that are built above the ground. An advanced building energy-modelling tool (DeST) that accounted for the impact of the surrounding soil environment was used to simulate the building's energy performance in the case of a prototype underground building. The simulation results of the indoor air temperature for an underground meeting room were compared with the onsite long-term measurement data, and yielded a good agreement, thus demonstrating that dealing with the thermal process of an underground building using DeST is accurate and feasible. Most importantly, the hourly heating and cooling loads were calculated by DeST, the relationships between the annual energy consumption and the U-values of the envelopes were detected for various climates in China. The following conclusions can be drawn:

(1) The temperature waves between the indoor temperature of underground spaces and the outdoor climate differ in terms of values, amplitude, and phase displacement, owing to the high thermal capacity of the surrounding soil.

(2) Conversely, with respect to underground buildings, implementing a similar building energy efficiency strategy manifested by the decrease in the U-values of the envelopes (enhancing the thickness of thermal insulation), may result in an increased energy consumption when the thermal performance of the envelopes is designed for underground buildings. 
(3) An improvement in the thermal performance of the roof plays an important role

558 in reducing the energy demands for the underground office building. The energy

559 efficiency requirements of roofs for the underground office buildings show

560 consistency with the standard adopted for buildings that are above the ground

561 (4) The optimal U-values of an exterior wall for underground office buildings are 562 completely different in the various climatic zones in China. For SCZ and CZ, the 563 optimal U-values are $0.8 \mathrm{~W} /\left(\mathrm{m}^{2} \cdot \mathrm{K}\right)$ and $1.0 \mathrm{~W} /\left(\mathrm{m}^{2} \cdot \mathrm{K}\right)$, respectively, while for 564 HSCWZ and TZ, the recommended optimal values are in the range of 1.5-2.0 $565 \mathrm{~W} /\left(\mathrm{m}^{2} \cdot \mathrm{K}\right)$. In terms of the building energy efficiency, thermal insulation is not 566 required for HSWWZ.

567 These conclusions were drawn for soil-buried office buildings and the 568 recommendations for optimal design U-values of building envelopes may not be 569 suitable for other building functions. A further study should be carried out to 570 investigate the impact of the thermal performance of building envelopes on annual 571 energy consumption for various building functions, such as underground shopping 572 malls, parking space, railways, hospitals, etc. In addition, the contact surface area of 573 building with the earth plays a key role in heat transfer with underground buildings, 574 and thus it is necessary to study the impact of contact surface area of building with the 575 earth on the energy consumption and the optimal U-values of building envelopes, and 576 further to correct these optimization results. 
This study was financially supported by China Construction Engineering Design

Group Corporation Limited (CSCEC-2014-Z-1-2).

\section{References}

[1] Nezhnikova E. The Use of Underground City Space for the Construction of Civil

Residential Buildings [J]. Procedia Engineering, 2016, 165:1300-1304.

584

[2] Zhao JW, Peng FL, Wang TQ, et al. Advances in master planning of urban underground space (UUS) in China[J]. Tunnelling \& Underground Space Technology Incorporating Trenchless Technology Research, 2016, 55:290-307.

[3] Yu RH, Ye QY. Review on the Development of Underground Shopping Mall in China[J]. Studies in Sociology of Science, 2012, 3(1).

[4] Shan M, Hwang BG, Wong KSN. A preliminary investigation of underground residential buildings: Advantages, disadvantages, and critical risks[J]. Tunnelling \& Underground Space Technology, 2017, 70:19-29.

[5] He L, Song Y, Dai S, et al. Quantitative research on the capacity of urban underground space - The case of Shanghai, China $[\mathrm{J}]$. Tunnelling \& Underground Space Technology, 2012, 32(11):168-179.

[6] Staniec M, Nowak H. Analysis of the earth-sheltered buildings' heating and cooling energy demand depending on type of soil[J]. Archives of Civil \& Mechanical Engineering, 2011, 11(1):221-235.

[7] Delmastro C, Lavagno E, Schranz L. Energy and underground[J]. Tunnelling \& 
Underground Space Technology Incorporating Trenchless Technology Research, 2016, 55(2925):96-102.

[8] Alkaff S A, Sim S C, Efzan M N E. A review of underground building towards thermal energy efficiency and sustainable development[J]. Renewable \& Sustainable Energy Reviews, 2016, 60:692-713.

[9] Al-Mumin AA. Suitability of sunken courtyards in the desert climate of Kuwait[J]. Energy \& Buildings, 2001, 33(2):103-111.

[10] Barker MB. Using the earth to save energy: Four underground buildings [J]. Tunnelling \& Underground Space Technology Incorporating Trenchless Technology Research, 1986, 1(1):59-65.

[11] Christian JE. Cooling season performance of an earth-sheltered office/dormitory building in Oak Ridge, Tennessee[J]. Klinicheskaia Meditsina, 1984, 162(12):7049-7057.

[12] Wang F. Mathematical modeling and computer simulation of insulation systems in below grade applications. Conference Thermal Performance of the Exterior Envelopes of Buildings; 1979.

[13] Liu J, Jiang Y, Jin Y A. Dynamic Model of Heat Transfer through Underground Building Envelope[C]// International Conference on Intelligent System Design and Engineering Application. IEEE Computer Society, 2010:649-652.

[14] Choi S, Krarti M. Thermally optimal insulation distribution for underground structures[J]. Energy \& Buildings, 2000, 32(3):251-265.

[15] Tinti F, Barbaresi A, Benni S, et al. Experimental analysis of shallow 
621

622

623

624

625

626

627

628

629

630

631

632

633

634

635

636

637

638

639

640

641

642

underground temperature for the assessment of energy efficiency potential of underground wine cellars[J]. Energy \& Buildings, 2014, 80:451-460.

[16] Peng C, Wang L, Zhang X. DeST-based dynamic simulation and energy efficiency retrofit analysis of commercial buildings in the hot summer/cold winter zone of China: A case in Nanjing[J]. Energy \& Buildings, 2014, 78(4):123-131.

[17] Nielsen TR. Simple tool to evaluate energy demand and indoor environment in the early stages of building design[J]. Solar Energy, 2005, 78(1):73-83.

[18] Lin YH, Tsai KT, Lin MD, et al. Design optimization of office building envelope configurations for energy conservation[J]. Applied Energy, 2016, 171:336-346.

[19] ASHRAE, ANSI/ASHRAE Standard 90.1-2010: Energy Standard for Building except Low-rise Residential Buildings, ASHRAE, Atlanta, GA, 2010.

[20] Design Standard for Energy Efficiency of Public Buildings. China Architecture and Building Press; 2015.

[21] Ma X, Cheng B, Peng G, et al. A numerical simulation of transient heat flow in double layer wall sticking lining envelope of shallow earth sheltered buildings[C]// International Joint Conference on Computational Sciences and Optimization. IEEE, 2009:195-198.

[22]Yuan Y, Cheng B, Mao J, et al. Effect of the thermal conductivity of building materials on the steady-state thermal behavior of underground building envelopes[J]. Building \& Environment, 2006, 41(3):330-335.

[23] Staniec M, Nowak H. Analysis of the energy performance of -earth-sheltered houses with southern elevation exposed [J]. 
643

644 simulations using a 55-year actual weather data set from China[J]. Applied Energy, $645 \quad 2017,195$.

646 [25] Yan D, Xia J, Tang W, et al. DeST - An integrated building simulation toolkit 647 648

[24] Cui Y, Yan D, Hong T, et al. Comparison of typical year and multiyear building Part I: Fundamentals[J]. Building Simulation, 2008, 1(2):95-110.

[26] Xie X, Jiang Y, Xia J. A new approach to compute heat transfer of ground-coupled envelope in building thermal simulation software[J]. Energy \& Buildings, 2008, 40(4):476-485.

[27] Zhang H, Liu J, Li C, et al. Long-term investigation of moisture environment in underground civil air defense work[J]. Indoor \& Built Environment, 2016.

[28] Xie XN, Song FT, Zhang XL, et al. Building environment design simulation software DeST (11): treatment of dynamic heat transfer through underground zone[J]. Heating Ventilating \& Air Conditioning. 2005, 35(6):55-63.

[29] Organization of Chinese Architecture Standards Design Institute. Design manual for air defense basement: HVAC[M].2006. 